\title{
Allocating irrigation water: the impact of strategic interactions on the efficiency of rules
}

\author{
Nicolas Faysse \\ International Water Management Institute, Pretoria, South Africa
}

Received February 2002; final version received June 2003

\section{Summary}

In many irrigation schemes, farmers are autonomous in decision making regarding cropping patterns. Some allocation rules currently used in such schemes share water according to what farmers cultivate but then permit an interaction among farmers' choices, whose outcome may be described as a Nash equilibrium. Such rules are compared with other existing and potential rules, when farmers differ in their individual abilities to create value from water. A model simulating the Nash equilibrium associated with farmers' cropping choices reproduces the overcropping pattern observed in an irrigation scheme in Tunisia and makes possible the recommendation of better allocation rules.

Keywords: water allocation, Nash equilibrium, common pool resources, revelation mechanism, Tunisia

JEL classification: D82, Q21, Q25

\section{Introduction}

In many irrigation schemes, the demand for water is greater than the supply allowed by the available infrastructure, mainly because farmers can afford to pay the operating costs but not the capital costs necessary to build new infrastructure. Moreover, in many of these schemes, farmers differ in their ability to create value from a given amount of water. Because of the shared nature of water as a resource or the presence of high transaction costs, the allocation of water among farmers is not made in a market place, but rather according to a collectively formulated rule. In reality, the allocation rule often allows farmers some room for manoeuvre with regard to the area they decide to cultivate. A combination of four factors can account for this freedom of choice. First, in some schemes, each farmer has a formal right to a given share of the total water available and can decide by himself what proportion of his land to irrigate. Second, in places where water is collectively owned, (i) the information costs regarding the farmers' ability to create value from water may be high, (ii) water scarcity may be a recent phenomenon and the allocation rule may have not been amended in keeping with it, or (iii) the rule may benefit some farmers who manage to block any proposed changes in it. 
Some of the allocation rules that allow farmers the choice of what proportion of their farms to cultivate create interdependences among farmers. In other words, the area one farmer chooses to cultivate will affect the amount of water obtained by the other farmers. Hereafter, such rules will be called ex post rules, because the allocations are decided after farmers' choices. For example, in some irrigation schemes in central Tunisia, an ex post allocation rule consists in a collective arbitration mechanism, which gives priority to market gardening over winter crops. Other allocation rules that do not create any interdependence are referred to here as ex ante rules, because the allocations are known before farmers' choices. For instance, a rule specifying that each farmer should receive a given share of the total volume of water, regardless of the actual area he cultivates, is an ex ante rule.

At first sight, ex post rules will create a non-co-operative game among farmers such that the result of the strategic interactions will usually not be a Pareto-optimal solution. Nevertheless, these rules are rather common: of 23 small-scale irrigation schemes studied by Schlager et al. (1994) in the Philippines, 30 per cent use a water turn system without any time limitation, i.e. creating interdependences, and 56 per cent use one that does not create any interdependence, either with a time-based allocation or with an allocation based on a proportion of the flow.

The purpose of this paper is to analyse under what circumstances such rules creating interdependences are able to create value in the whole scheme, given the setting described in the opening paragraph; that is, in cases where (i) the demand for water is greater than its supply, (ii) water is allocated centrally by a Manager, (iii) farmers differ in their ability to create value from water and (iv) farmers can choose what proportion of their farm area to cultivate. It is assumed that the Manager does not know the ability of each farmer. If the Manager knew the farmers' abilities, he would be able to allocate water so as to create the maximum total value and subsequently effect transfers among farmers so as to meet equity objectives.

Previous papers have compared the efficiency of different allocation rules. On the one hand, some studies have used applied models to compare different allocation rules, but without any change in the cropping pattern. Steiner and Walter (1992) compared the efficiency of allocation rules with different degrees of seepage losses in the canals. They found that an ex ante rule creates the greatest value as long as the technical efficiency of distribution is above a given threshold. For an efficiency lower than this threshold, an ex post rule that gives priority to upstream farmers leads to a better total created value. Small and Rimal (1996) also used an applied model to compare the outcome of different rules, but they based their model on different levels of water scarcity, for a given degree of heterogeneity among users created by seepage losses. They focused especially on one rule that will not be discussed here except to say that it aims to minimise conveyance losses. They showed that this rule produces results that are close to those of the rule that aims to maximise total value, especially at high levels of water scarcity. 
On the other hand, other papers have used simple game theoretical models for looking at the strategic interactions among players, but they have adopted fixed payoff matrixes and hence have failed actually to describe and compare the different possible allocation rules. For instance, Baland and Platteau (1999) studied a common pool resource dilemma in a fishery using an ex post mechanism. They showed that wealth heterogeneity raises the propensity for rich members to co-operate whilst lessening the incentive for poor members to do so. Hence, depending on the shape of the production function and the parameters of the game, greater heterogeneity may lead to a decrease in collective action but may also lead to an increase, as Olson contended it would in his seminal analysis (Olson, 1965).

This paper tries to combine the two approaches, by both taking into account farmers' strategic choices and describing different allocation and taxation rules, first in a theoretical model, and then with an applied model based on simple but realistic agricultural production functions. DaytonJohnson (2000a, 2000b) analysed the congruency between rules for sharing maintenance costs and water allocation rules, with farmers being free to choose how much to contribute to maintenance. Nevertheless, his models do not allow a direct comparison of the efficiency of different pairings of allocation and taxation rules. In fact, the size of the literature describing and analysing the efficiency of allocation rules when strategic behaviour is taken into account is much smaller than the entire literature that studies strategic behaviour given different cost-sharing rules (e.g. Moulin, 1988).

Finally, even though the question asked here focuses on allocation rules in an irrigation scheme, it is in fact valid for all common pool resources for which individual profit depends on an initial individual investment, for example, in fisheries (Platteau and Seki, 1998).

This study is twofold. First, a theoretical model compares the results of different allocation rules. The outcome of the strategic interactions between farmers is represented at the Nash equilibrium, which is unique given the theoretical setting. A revelation mechanism can lead to the optimal created value in the scheme, but the taxes levied through this mechanism are not necessarily sufficient to pay the water provision costs. The comparison of different possible rules shows that ex post rules can lead to a satisfactory total created value if the group is heterogeneous, but will often lead to large differences in farmers' profits. This problem of equity can be solved if the ex post rule is coupled with a high tariff, with the revenue collected from taxes being redistributed to meet an equity objective. On the whole, the ex post rules can sometimes be considered as efficient because they function as an indirect revelation mechanism.

Second, in the context of a small-scale irrigation scheme in Tunisia, the actual ex post allocation rule is compared with other possible ones through an empirical analysis. An algorithm is used to model the Nash equilibrium associated with farmers' choices regarding the areas cultivated for a given ex post rule. The rule in use turns out to create less value than both an ex ante rule and an alternative ex post one. 
The paper is organised as follows. Section 2 presents the theoretical setting. The optimal allocation rule is also characterised when there is no information asymmetry (Section 3). Section 4 deals with the situation where the Manager knows only the total distribution of abilities. A revelation mechanism is defined, then different possible allocation rules are characterised and compared with one another, in relation to group heterogeneity. Finally, a comparison is made between existing and other potential allocation rules in the case of a Tunisian irrigation scheme (Section 5). Section 6 concludes.

\section{The theoretical setting}

Here we consider an irrigation scheme made up of a set $\mathrm{I}=\{1, \ldots, n\}$ farmers. The overall process starts with the Manager announcing the given management rules that will be used: a water allocation function and a monetary transfer function. The same functions will be used to calculate the water allocations and the fees for all farmers, but their values will differ from one farmer to another, depending on what farmers grow. The total available volume $V$ of water that will be shared among farmers is exogenous and already known. Then, all farmers simultaneously choose the area they want to cultivate. In the cases where the Manager uses an ex post allocation rule, such a setting can be described as a non-co-operative game: the water received by each farmer depends on other farmers' farming choices, hence each farmer will independently and simultaneously make an assumption about other farmers' choices in order to decide what to crop. Once the Manager knows the areas under various crops, he can decide on individual water shares and calculate the fee that each farmer will pay. Finally, water is distributed to farmers and payments are made.

At farmer level, all farmers cultivate the same crop. The yield $r$ of this crop, expressed in monetary unit per hectare, is a strictly increasing and concave function $C^{1}$ of the overall water used. The overall scarcity context entails that it is not necessary to take into account the part of the yield function corresponding to large volumes of water applied per hectare, which may be constant or even decreasing.

It is assumed that each farmer decides to plant an area $s_{i}$ requiring irrigation. Furthermore, a maximum area $s_{m}$ can be cultivated. It is assumed that the farmer does not receive any profit from the uncropped land $\left(s_{m}-s_{i}\right)$. Each farmer will obtain a fraction $V_{i}$ of the overall volume of available water, $V$, and will distribute it evenly over the area $s_{i}$ he has chosen. ${ }^{1}$ The farmer also pays inputs costs $k . s_{i}$ that are assumed to be proportional to the area he cultivates. These costs do not include water costs. Finally, let $a_{i}$ be an individual coefficient that represents the farmer's capacity to create value from water, a capacity that reflects such variables as his technical knowledge or the soil quality of his field. Moreover, it is assumed that each 
farmer has a distinct ability coefficient: the set $\mathrm{I}=\{1, \ldots, n\}$ is then ordered so that $\left(a_{i}\right)_{i \in \mathrm{I}}$ is strictly decreasing in I. The value of the production achieved per hectare is $a_{i} r\left(V_{i} / s_{i}\right)$. Hence, the farmer's surplus will be $s_{i}\left[a_{i} r\left(V_{i} / s_{i}\right)-k\right]$. It is also assumed that, for all farmers, a minimum amount of water is necessary to cover input costs: $\forall i \in \mathrm{I}, a_{i} r(0)<k$.

Finally, there are also some water production costs that are assumed to be linear with volume; $w_{0}$ denotes the water production costs per unit of volume. Let $g$ be a function defined by $g(u)=r(u)-u r^{\prime}(u)$, with $g^{(-1)}$ being the inverse function of $g$ (well defined as $r$ is strictly increasing and concave). Each farmer is assumed to maximise his revenue. If a farmer knows from the onset that he will obtain a certain volume $V_{0}$, he will plant an area $s_{i}^{*}$. Then, provided $s_{i}^{*} \leq s_{m}$, he will apply a given volume per hectare $v_{i}^{*}=g^{(-1)}\left(k / a_{i}\right)$ whatever the value of $V_{0}$ (see proof in Appendix 1). In the Introduction, it was assumed that farmers could afford to pay water production costs. Hence, we assume here that every farmer receives a positive revenue for this optimal volume per hectare, if he has to pay for water production costs. Thus, if the farmer wants to use the entire volume allotted to him $\left(V_{0} \leq s_{m} v_{i}^{*}\right)$,

$$
\pi_{i}=\frac{V_{0}}{v_{i}^{*}}\left[a_{i} r\left(v_{i}^{*}\right)-k\right]-w_{0} V_{0}>0 .
$$

Consequently, we assume that

$$
\forall i \in \mathrm{I}, \quad a_{i} r\left[g^{(-1)}\left(\frac{k}{a_{i}}\right)\right]>w_{0} g^{(-1)}\left(\frac{k}{a_{i}}\right)+k .
$$

At the scheme level, in order to allocate water and to levy fees, the Manager knows the total available volume $V$ and the areas cultivated by each farmer $\left(s_{i}\right)_{i \in \mathrm{I}}$. In Section 3 below, it is assumed that the Manager knows the coefficient of value creation for every farmer, whereas in Section 4 this assumption is restricted: the Manager knows only the global distribution without being able to assess the ability of any given farmer. It is also assumed that a farmer is influenced by other farmers' choices only through the total area under cultivation. In other words, farmer $i$ 's choice $s_{i}$ will not depend on the $(n-1)$ vector $\left(s_{1}, \ldots, s_{i-1}, s_{i+1}, \ldots, s_{n}\right)$ but simply on the total area $S=\sum_{i \in \mathrm{I}} s_{i}$. Besides, we consider a scheme where the number of farmers is large enough so that it is possible to consider $s_{i} \ll S$.

A common function $f$ is used to define the allocation of water to each farmer. A farmer $i$ receives an amount of water that depends on the parameters described above: $V_{i}=f\left(a_{i}, s_{i}, S\right) V$. The only constraint necessary to define such a function is that it should comply with the global constraint on the available water: $\sum_{i \in \mathrm{I}} f\left(a_{i}, s_{i}, S\right) \leq 1$. For instance, $f\left(a_{i}, s_{i}, S\right)=s_{i} / S$, or $f\left(a_{i}, s_{i}, S\right)=1 / N$.

A common monetary transfer function is defined with the same arguments. Each farmer $i$ pays a sum $t_{i}=t\left(a_{i}, s_{i}, S\right)$, which can be either a fee paid to the Manager or a transaction made on a market. In the latter case, this sum might be negative. With such a setting, an allocation or monetary transfer rule will create an interdependence among farmers, hence lead to a game setting and be 
of the ex post type, if and only if $S$ is used to calculate the value of the function. Besides, although the input costs remain the responsibility of each farmer, the Manager must pay the water production costs. Hence, the function $t$ must satisfy a global budgetary constraint, $\sum_{i \in \mathrm{I}} t_{i} \geq w_{0} \sum_{i \in \mathrm{I}} V_{i}$.

In such a context, farmer $i$ 's choice of area is the solution of the decision

$$
\operatorname{Max}_{s_{i}} \pi_{i}=s_{i}\left\{a_{i} r\left[\frac{f\left(a_{i}, s_{i}, S\right) V}{s_{i}}\right]-k\right\}-t\left(a_{i}, s_{i}, S\right)
$$

such that $s_{i} \leq s_{m}$.

Henceforth, we distinguish between the profit of a farmer, which is net of taxes, and the created value, which is not.

The Manager is assumed to maximise the value created in the whole scheme: $\Pi=\pi_{1}+\cdots+\pi_{n}$.

Finally, in this paper, the efficiency of a rule is defined as its ability to create value in the whole scheme (the equity impacts of a rule will not be part of the formal model being proposed here and will be discussed only qualitatively).

Two different situations are analysed. The first one relates to the case where the Manager knows all farmers' abilities. The following section shows that, in this case, the potential maximum of created value can be attained. In the second situation, analysed in Section 4, the Manager knows only the global distribution of individual parameters. In such a case, the Manager can still write his objective function as a sum of individual profit functions, even if he is not able to link a given index to a specific farmer.

There is no point in studying the case where the Manager has no information on the ability coefficients (and thus not even the distribution of parameters) because then he does not know the individual profit functions, which are based on the ability coefficients. Because his own objective function, $\Pi$, is the sum of these individual profit functions, the Manager cannot calculate the function he has to maximise. He cannot then compare the results of different possible management rules. In such a situation, as well as in the previous ones, an alternative would be to set up a market, but its nature would be very different from the management functions studied here.

Proposition 1. A market can attain the potential maximum created value for the whole scheme.

This proposition is demonstrated in Appendix 2. However, markets are not commonly used, as (i) water may not be considered as a tradable good (Gillingham, 1999), (ii) water rights may not be sufficiently defined in legal terms or may not be recognised by the State (Bédoucha, 1984), or (iii) the associated transaction costs may be too high (Garrido, 2000).

\section{The Manager knows all farmers' abilities}

Here the Manager is assumed to know all the farmers' coefficients. Through the use of dissuasive taxes, he can dictate the area cultivated by each farmer. In such a case, the Manager can achieve the maximum of created value in the 
scheme. The Manager's decision problem is

$$
\underset{s_{i}, V_{i}}{\operatorname{Max}_{i}} \sum_{i \in \mathrm{I}} s_{i}\left[a_{i} r\left(\frac{V_{i}}{s_{i}}\right)-k\right]-w_{0} V_{i}
$$

such that $\sum V_{i} \leq V$ and $\forall i \in \mathrm{I}, s_{i} \leq s_{m}$.

Proposition 2. When the Manager knows each individual's capacity, he can differentiate two groups of farmers in order to reach the maximum total created value:

- Farmers 1 to q cultivate the entire area they own. The pivotal farmer $q$ and the coefficient $\lambda$ are defined by the two equations $a_{q} g\left[\left(r^{\prime}\right)^{(-1)}\left(\lambda / a_{q}\right)\right]=k$ and $V=s_{m} \sum_{i=1}^{q}\left(r^{\prime}\right)^{(-1)}\left(\lambda / a_{i}\right)$.

- No cropping is undertaken by farmers $q+1$ to $n$.

This is shown in Appendix 3. Henceforth, the water allocation described in this proposition will be called the 'optimal allocation'.

Another possible allocation consists in giving water to only the most competent farmer. With the assumption of equation (1), whatever the total volume $V$, the profit is positive after having paid water production costs. Because the optimal allocation gives a better collective profit than this one, the profit for optimal allocation is positive. Besides, here the Manager can impose all variables: there is no strategic interaction between farmers. In some rare irrigation schemes, the water allocation depends indeed on the potential for creation of value. In some irrigation schemes managed by users' associations in Colombia, for instance, the areas that farmers can cultivate depend on soil characteristics (Vermillion and Garces-Restrepo, 1996).

\section{The Manager knows only the distribution of farmers' abilities}

Here we assume that the Manager knows the global distribution of the farmers' abilities, although he is not able to ascribe a precise value to each farmer. This is all the more possible when the farmers' abilities do not change and the Manager succeeds in obtaining information about the farmers' capacities year after year. For example, he may have constructed a farm typology based on a partial survey. As the Manager does not know the ability of a given farmer, the management functions are now of the form $f\left(s_{i}, S\right)$ and $t\left(s_{i}, S\right)$.

We assume that the outcome of the strategic interactions, when farmers choose the area to plant, can be represented by a Nash equilibrium. Let $\tilde{s}_{i}(S)$ be farmer $i$ 's reaction function, i.e. the area he chooses if he assumes that the total area cultivated will be $S$. Then, let $\tilde{S}=\sum_{i \in \mathrm{I}} s_{i}=F(S)$. Faysse (2001) shows that, with some realistic constraints on $f$ and $t, F$ is continuous and decreasing. From assumption (1), $F(0)>0$. Furthermore, we can assume that, if every farmer cultivates his entire area, at least one farmer will not be satisfied and will want to grow less: $F\left(n s_{m}\right)<n s_{m}$. Then, using a fixed point theorem, there is a unique Nash equilibrium. 
The Manager will choose the allocation and taxation rules that maximise the created value, given the constraint that farmers' choices correspond to a Nash equilibrium and the two constraints on the management functions $f$ and $t$. The Nash equilibrium is represented as a constraint of equilibrium between the strategic choices of all farmers:

$$
\forall i \in \mathrm{I} \quad s_{i}=\operatorname{Arg} \operatorname{Max}_{i}\left\{a_{i} r\left[\frac{f\left(s_{i}, S\right) V}{s_{i}}\right]-k\right\}-t\left(s_{i}, S\right)
$$

such that $s_{i} \leq s_{m}$, where, as defined above, $S=\sum_{i} s_{i}$. Hence, the Manager solves the following problem:

$$
\operatorname{Max}_{f, t} \sum_{i \in \mathrm{I}}\left(s_{i}\left\{a_{i} r\left[\frac{f(s i, S) V}{s_{i}}\right]-k\right\}-t\left(s_{i}, S\right)\right)
$$

such that

$$
\begin{gathered}
\forall i \in \mathrm{I} \quad s_{i}=\operatorname{Arg} \operatorname{Max}_{i}\left\{a_{i} r\left[\frac{f\left(s_{i}, S\right) V}{s_{i}}\right]-k\right\}-t\left(s_{i}, S\right) \quad \text { for } s_{i} \leq s_{m} \\
\sum_{i} f\left(s_{i}, S\right) \leq 1 \\
\sum_{i} t\left(s_{i}, S\right) \geq w_{0} \sum_{i} f\left(s_{i}, S\right) V .
\end{gathered}
$$

For the Manager, the knowledge of the distribution of farmers' abilities is sufficient to solve this problem.

In such a context, it is possible to design a revelation mechanism that will attain the best total added value (Section 4.1). However, transaction costs or, more importantly, the Manager's failure to cover operating costs with the revenue from fees may pose problems in setting up such a mechanism. Moreover, it is not possible to solve equation (4) in such a general setting. Hence, different existing and possible rules are described and analysed (Section 4.2). The theoretical setting is nevertheless too general to provide a basis for comparing these different rules. Hence, Section 4.3 presents an example with a given production function and a given representation of farmer homogeneity. Such choices lead to a greater specificity, and the results provide a good understanding of the consequences of each rule and how they compare with each another. It shows how a Manager, who knows both the production function and the distribution of abilities, can compare the results of different management rules.

\subsection{A revelation mechanism}

As before, the Manager still needs to meet the constraints on volume and budget. However, the overall process is slightly different from the one presented in the previous subsection. The Manager will allocate water and tax the farmers according to the ability coefficients they choose to announce. It is shown that, for a given couple of functions, it is possible to achieve the optimum of value creation. Such an optimum could not be achieved with a revelation mechanism based on farmers' choice of area under crop. Indeed, 
the Manager would not then be able to differentiate between farmers who put their entire surface $s_{m}$ under crops, but who should receive different amounts of water depending on their ability coefficient, so as to attain the optimum of value creation.

As the Manager knows the distribution of coefficients, he can calculate the coefficient $a_{q}$ of the pivotal farmer $q$ for the optimal allocation, as well as the Lagrangian multiplier $\lambda$ associated with the constraint $\sum_{i} f\left(s_{i}, S\right) \leq 1$ in the programme (3) of the optimal allocation. The value of $q$ and $\lambda$ are defined by the equations of Proposition 2. The Manager is going to build the mechanism around this pivot farmer, $q$. He will use these two coefficients, $a_{q}$ and $\lambda$, so as to obtain the optimal allocation, i.e. a situation where all farmers whose coefficient is lower than that of the pivot farmer $q$ eventually do not crop anything, and those with a higher coefficient put all their arable land under crops.

The revelation mechanism is designed as follows. First, the Manager announces the functions $f_{r}(\tilde{a})$ and $t_{r}(\tilde{a})$ that will be used to allocate water and tax each farmer depending on the coefficient $\tilde{a}$ the latter chose to declare. The functions are based on the following principles. Each farmer can choose to declare a coefficient $\tilde{a}$ lower than $a_{q}, q$ being the pivot farmer for optimal allocation. The Manager will then require him not to crop, will not give him any water and will not tax him. If the farmer chooses to declare a coefficient $\tilde{a}$ greater than or equal to $a_{q}$, then the Manager will require him to put his whole land $s_{m}$ under crop. Moreover, in this second case, the volume granted by the Manager and the tax levied will depend on the coefficient announced, with the following functions:

$$
\begin{gathered}
f_{r}(\tilde{a})=\frac{s_{i}}{V}\left(r^{\prime}\right)^{(-1)}\left(\frac{\lambda}{\tilde{a}}\right) \\
t_{r}(\tilde{a})=s_{i}\left\{\tilde{a} \cdot r\left[\left(r^{\prime}\right)^{(-1)}\left(\frac{\lambda}{\tilde{a}}\right)\right]-\int_{a_{q}}^{a_{i}} r\left[\left(r^{\prime}\right)^{(-1)}\left(\frac{\lambda}{u}\right)\right] \mathrm{d} u\right\} .
\end{gathered}
$$

Second, once all farmers know the functions used for allocation and taxation, they announce the coefficient they want to declare to the Manager and crop either nothing or the whole area, depending on the coefficient they announced.

Finally, the Manager gathers all the announcements, allocates water and taxes the farmers. In such a context, each farmer can decide either to announce a coefficient lower than $a_{q}$, grow nothing and pay nothing-his profit will be nil - or to declare a coefficient greater than $a_{q}$ and plant an area $s_{m}$. In the latter case, he will choose his announcement $\tilde{a}_{i}$ by maximising the following pay-off:

$$
\operatorname{Max}_{\tilde{a}_{i}} \pi_{i}=s_{m}\left\{a_{i} r\left[\frac{f_{r}\left(\tilde{a}_{i}\right) V}{s_{i}}\right]-k\right\}-t_{r}\left(\overleftrightarrow{a}_{i}\right) .
$$

such that $\pi_{i} \geq 0$.

Proposition 3. With the functions $\left(f_{r}, t_{r}\right)$, each farmer announces his true ability coefficient $a_{i}$. The revelation mechanism defined by $\left(f_{r}, t_{r}\right)$ achieves the optimum for creation of value. 


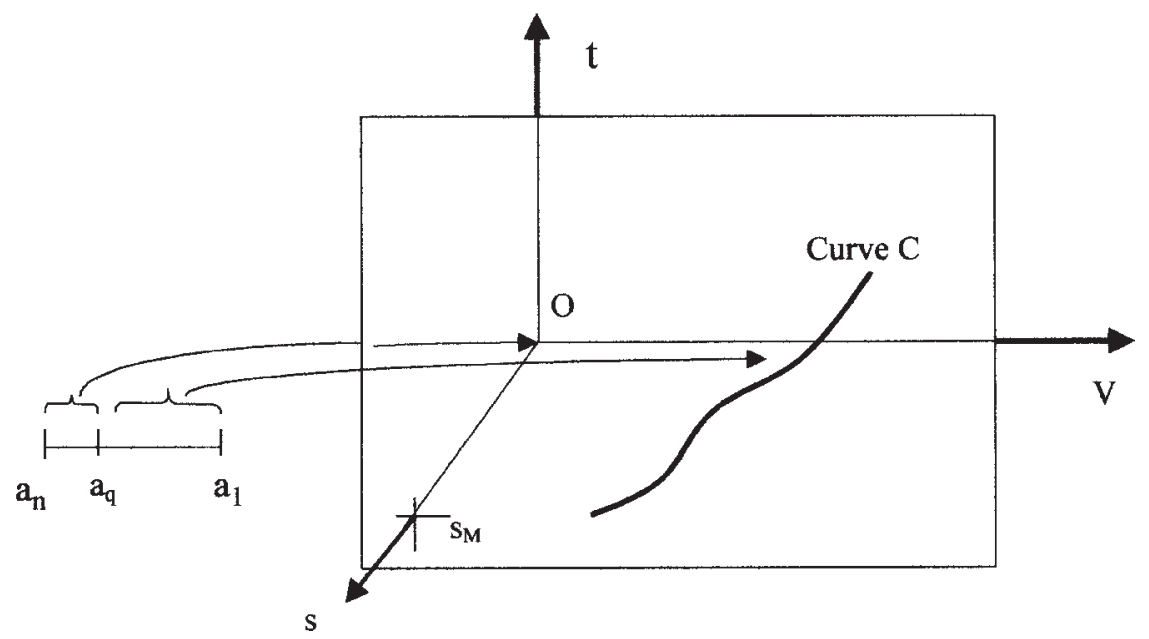

Figure 1. Set $\{O\} \cup C$ of the optimal allocation, with $C$ contained in plan $\left(s=s_{m}\right)$.

However, the revelation mechanism can be implemented only if the water production costs can be paid:

$$
\sum_{i=1}^{q} t_{r}\left(a_{i}\right) \geq w_{0} V .
$$

A proof of this proposition is given in Appendix 4.

The profit per farmer is thus zero for $i>q$ and, for $i \leq q$,

$$
\pi\left(a_{i}\right)=s_{m} \int_{a_{q}}^{a_{i}} r\left[\left(r^{\prime}\right)^{(-1)}\left(\frac{\lambda}{u}\right)\right] \mathrm{d} u .
$$

Figure 1 depicts the set of all possible contracts, i.e. the origin $\mathrm{O}$ and the curve $C$ belonging to the plan $\left(s=s_{m}\right) . C$ is the set of points $\left[f_{r}\left(a_{i}\right), t_{r}\left(a_{i}\right)\right]$ when $i$ takes all values in the subset of I corresponding to $s=s_{m}$. The 'curve' $C$ is monotonic, as the volume per hectare $v_{i}^{*}$ is decreasing in $i$ (compare Appendix 3 ). The set of points $C$ and the origin $\mathrm{O}$ describe both the revelation mechanism and the optimal allocation.

Usually, a revelation mechanism does not attain the first-best optimum because it has to give a rent to the most competent farmers to induce them to reveal their type, and this rent is detrimental to the Manager. Here, the rent does not prevent the attainment of the maximal created total value.

However, in this model, there is no guarantee that the taxes levied by the Manager satisfy $\sum_{1}^{q} t_{r}\left(a_{i}\right)>w_{0} V$. In some cases, the rent system necessary to induce farmers to reveal their type will not be adequate for collecting enough money to pay water production costs. In such circumstances the revelation mechanism cannot be used.

It is also possible to design a tax equivalent to the revelation mechanism, thanks to the taxation principle (Guesnerie, 1995). In the situation described 
here, a single pair of allocation and taxation functions based only on the area cultivated would not be sufficient, as it would not be able to separate farmers who cultivate their entire arable area. One must, therefore, let farmers choose both the area and the volume of water they want to use, and tax them according to these choices.

Proposition 4. It is possible to build a taxation function $\tau(s, V)$, which allows the achievement of the maximum of created value. The taxation function is defined as follows:

- $\tau(0,0)=0$;

- $\forall\left(s_{i}, V_{i}\right) \in C, \exists ! a_{i} ; V_{i}=s_{i}\left(r^{\prime}\right)^{(-1)}\left(\lambda / a_{i}\right)$, where $\lambda$ is the multiplier calculated for the preceding optimal allocation, then $\tau\left(s_{i}, V_{i}\right)=t_{r}\left(a_{i}\right)$;

- $\forall\left(s_{i}, V_{i}\right) \in \Re^{2} \backslash\{C \cup(0,0)\}, \tau\left(s_{i}, V_{i}\right)=M$, where $M$ is any dissuasive value.

However, in practice, a dissuasive value $M$ would not be accepted by the farmers, therefore the preceding taxation system may be easily replaced by a set of contracts $(V, s, t)$ based on the set of points $C$ and the origin $\mathrm{O}$.

\subsection{Different possible management rules}

Hereafter, the ex ante water allocation rule will designate only $f\left(s_{i}, S\right)=1 / n$, whereas the ex post one will be defined by $f\left(s_{i}, S\right)=s_{i} / S$. Apart from these two rules, a mixed rule between ex ante and ex post allocation rules will be analysed. These three allocation functions are associated with the standard taxation function: $t\left(s_{i}, S\right)=w f\left(s_{i}, S\right) V$, where $w$ stands for a volumetric tariff that can be chosen higher than or equal to the water production costs $w_{0}$.

\subsubsection{Ex ante allocation}

Each farmer knows before the beginning of the period that he will obtain a given share of the volume that is not linked to his individual capacity to create value from water $a_{i}$. Assuming equal shares, this means that each farmer receives $V / n$. So, each farmer independently maximises

$$
\pi_{i}=s_{i}\left[a_{i} r\left(\frac{V}{n \cdot s_{i}}\right)-k\right]-w \frac{V}{n} .
$$

If the optimal cropped area $s_{i} \leq s_{m}$, then: $v_{i}=V /\left(n . s_{i}\right)=g^{(-1)}\left(k / a_{i}\right)$ (using the case of a single farmer; see Appendix 1). The function $g^{(-1)}$ increases so $v_{i}$ decreases in $a_{i}$ and hence increases in $i$. This implies that less skilled farmers irrigate more per hectare and, thus, cultivate smaller areas. Besides, the marginal values of water are different across farmers, creating a potential for reallocation.

Obviously, the ex ante allocation makes it possible to reach the collective optimum of created value only if farmers' capacities are identical.

\subsubsection{Ex post allocation}

Here, each farmer receives a volume $V_{i}=s_{i} V / \sum s_{i}$. Farmers' choices are interdependent and the volume per hectare is the same for all farmers: 
$v^{*}=V / \sum s_{i}$. The profit per individual is

$$
\pi_{i}=s_{i}\left[a_{i} r\left(\frac{V}{S}\right)-k-w \frac{V}{S}\right] .
$$

The assumption was made in the model that $s_{i} \ll S$. Let us define $S_{-i}=S-s_{i}$. Then,

$$
\pi_{i}=s_{i}\left\{a_{i} r\left[\frac{V}{S_{-i}\left(1+\frac{s_{i}}{S_{-i}}\right)}\right]-k-w \frac{V}{S_{-i}\left(1+\frac{s_{i}}{S_{-i}}\right)}\right\} .
$$

Using the power series expansion for $\pi_{i}$ to order one of $s_{i} / S$, we can obtain the following approximation:

$$
\pi_{i} \approx s_{i}\left[a_{i} r\left(\frac{V}{S_{-i}}\right)-k-w \frac{V}{S_{-i}}\right] .
$$

Therefore, it is possible to consider that, to an approximation of order one, profit is a linear function of the area under crops, $s_{i} / S$. Let $p(w)$ be the pivotal farmer, for whom

$$
a_{p(w)} r\left[\frac{V}{s_{m} p(w)}\right]=k+w \frac{V}{s_{m} p(w)} .
$$

Then, on the one hand, the farmers $j$ for whom

$$
a_{j} r\left[\frac{V}{s_{m} p(w)}\right]>k+w \frac{V}{s_{m} p(w)}
$$

will maximise their cropped area. On the other hand, those for whom

$$
a_{i} r\left[\frac{V}{s_{m} p(w)}\right]<k+w \frac{V}{s_{m} p(w)}
$$

will not cultivate any land.

Proposition 5. With an ex post allocation, the capable farmers-up to pivotal farmer $p(w)$-cultivate all their land whereas the others do not cultivate at all. The pivotal farmer is defined by

$$
a_{p(w)} r\left[\frac{V}{s_{m} p(w)}\right]=k+w \frac{V}{s_{m} p(w)} .
$$

When compared with the optimal allocation, there is overcropping as long as the volumetric tariff

$$
w<s_{m} q\left[a_{q} r\left(\frac{V}{s_{m} q}\right)-k\right] / V
$$

where $q$ is the pivotal farmer for optimal allocation.

This proposition is demonstrated in Appendix 5. Similarly, DaytonJohnson (2000a) shows that in an irrigation scheme where costs are shared 
equally among farmers and where water allocation is proportional to the land owned by each farmer, only a limited number of farmers will decide to plant and be active members of the scheme.

\subsubsection{Mixed allocation between ex ante and ex post rules}

Because ex post or ex ante allocation rules are more or less efficient depending on group heterogeneity, it may be of interest to study a rule that combines both. The mixed allocation is of the following form:

$$
f\left(s_{i}, S\right)=\beta \frac{V}{n}+(1-\beta) \frac{V s_{i}}{S} .
$$

The parameter $\beta$ varies from zero (ex post allocation) to one (ex ante allocation). The Manager may look for the $\beta$ that maximises the total value of water.

\subsection{Comparison of allocation rules with a square root form yield function}

Let us assume that $r(v)=\sqrt{v}^{2}$ For each farmer, let $a_{p}=1 / p_{\alpha}$ be the farmer's ability to create value from water. When $\alpha$ is close to zero, the group is homogeneous and its heterogeneity increases as the value of $\alpha$ increases.

Two kinds of ex post allocation rules are calculated:

- when the volumetric tariff $w$ is zero (e.g. farmers may pay a lump sum fee for water delivery) or is a negligible sum compared with the fixed cost per hectare $k$;

- when farmers pay the volumetric tariff $w$ that optimises the creation of value for the whole scheme ( $w$ will depend on $\alpha$ ).

The formulae defining water allocation rules have been calculated with $n=V=1000, k=1$ and $s_{m}=1 .^{3}$ The degree of heterogeneity $\alpha$ varies from zero to 0.3 . For $\alpha=0.01$, the coefficients $a_{i}$ vary from one to 1.07 whereas with $\alpha=0.3$, the range of variation is from one to eight. An optimisation algorithm permits the discovery of an optimal $\beta$ for a given degree of group heterogeneity.

Figure 2 depicts the area cultivated by each individual farmer for a given allocation rule and for a rather homogeneous group $(\alpha=0.05)$. This figure shows that there are two groups of rules.

- A group of rules where a pivot farmer defines a frontier between the farmers who cultivate the whole arable area they own and those who cultivate nothing. The optimal allocation belongs to this group, as do two other rules leading to an overcropping situation, which are the two ex post allocation rules.

2 There is no need to consider the derivative problem at zero as the presence of a cost $k>0$ per hectare implies that all calculations are made far from the origin.

3 Faysse (2001) gives the mathematical expressions of the results of the different rules studied in this model. 


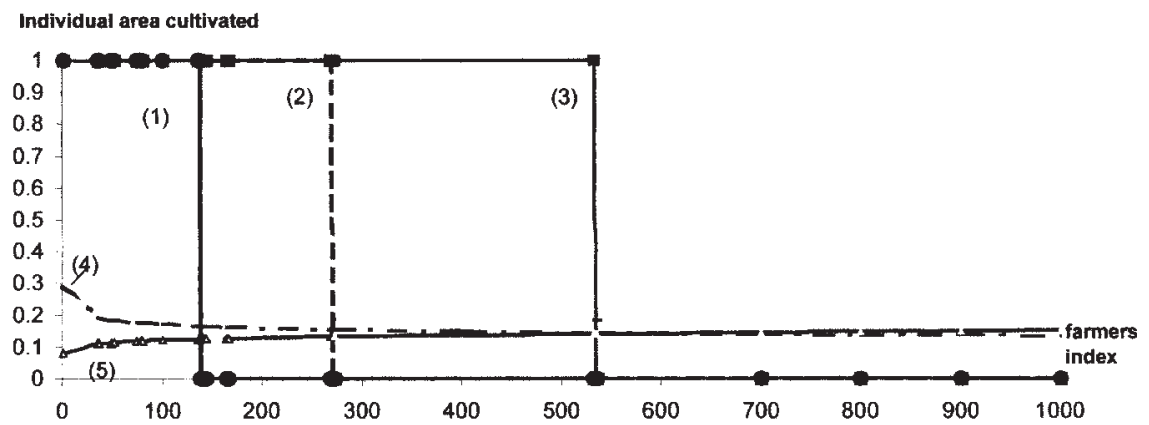

Figure 2. Area cultivated per farmer for $\alpha=0.05$ for the various allocations. (1) Optimal allocation; (2) ex post allocation with optimal tax; (3) ex post allocation without tax; (4) mixed allocation between ex ante and ex post; (5) ex ante allocation.

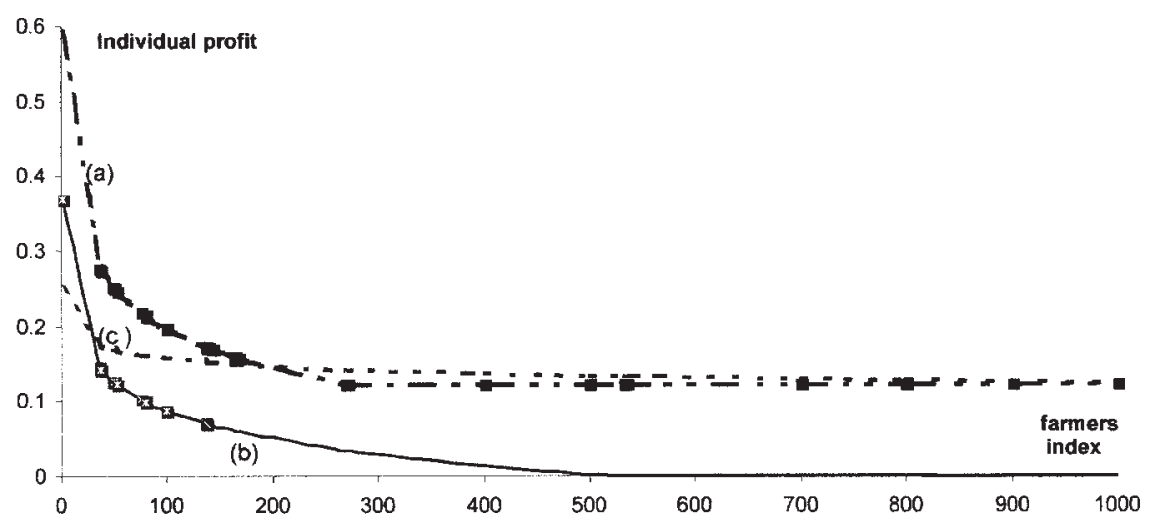

Figure 3. Profit per individual (with taxes equally redistributed) for $\alpha=0.05$. (a) Ex post allocation with optimal tax; (b) ex post allocation without tax; (c) ex ante allocation and mixed allocation between ex ante and ex post.

- A group of rules where every farmer cultivates a part of his arable land. This group contains the ex ante rule and the mixture of ex ante and ex post rules.

Figure 3 shows the profit per individual for the same degree of homogeneity as Figure 2. The profit per individual takes into account the taxes levied and their equal redistribution among farmers. Optimal allocation (not represented here) allows a profit ranging from 2.3 for farmer 1 to one for the pivot farmer. Because the ex ante and mixed allocation curves are close to each other, they have been merged. This figure illustrates the different degrees of inequity of the different allocation rules.

Finally, Figure 4 presents the ratio between the total created values for a given allocation and for the optimal allocation. The created value associated with a given rule has been represented using this ratio because the optimal created value changes with group heterogeneity. 
Total created value for a given allocation divided by the total created value for the optimal allocation

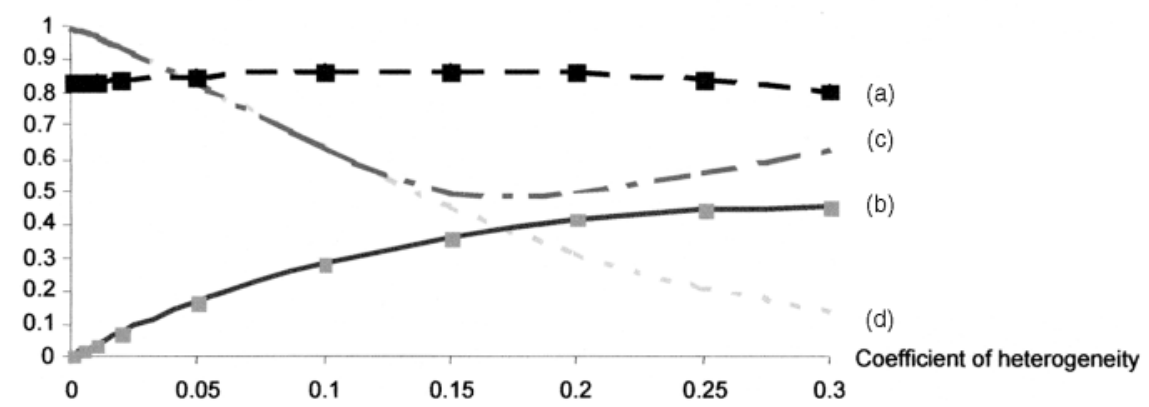

Figure 4. Ratio between the created values for a given allocation and for the optimal allocation. (a) Ex post allocation with optimal tax; (b) ex post allocation without tax; (c) mixed allocation between ex ante and ex post; (d) ex ante allocation.

The first result is that the ex ante rule leads to a satisfactory total created value when the group is homogeneous, whereas the ex post rule with a low water tariff leads to a superior created value when the group is heterogeneous. This result has also been shown by Steiner and Walker (1992).

In fact, the ex post rules allocate more water to the most capable farmers. Therefore, these rules can lead to a satisfactory created value when the group is heterogeneous because they function as an indirect revelation mechanism. Nevertheless, to give incentives to capable farmers to reveal their abilities, the rules must reward them. This will lead to large differences in farmers' revenues, as a result of which these rules may be considered as unequal. However, the ex post rule associated with a high water tariff (optimised here for every degree of heterogeneity) proves capable of creating a satisfactory total value and also almost Pareto-dominates all other rules (Figure 3). The reason is that the equal redistribution of the taxes collected gives the same results as a system where each farmer owns a part of the collective resource and is compensated if another farmer uses his water share.

Proposition 6. Given the theoretical setting, the choice of production function and a distribution of heterogeneity, the following results are obtained.

- Regarding the total value created from water, the more homogeneous the group, the closer the ex ante allocation is to the optimal allocation, whereas the greater the group's heterogeneity, the closer the ex post allocation is to the optimum allocation.

- For a rather homogeneous group, the ex ante and mixed allocations are broadly equivalent in terms of total cropped area and total created value.

- Mixed allocation allows a significant gain compared with both the ex ante rule and the ex post rule without tax, when the group is heterogeneous.

- An ex post allocation coupled with a high water tariff can lead to a satisfactory total created value, whatever the degree of heterogeneity. 
The model could also be used to take into account other types of heterogeneity, affecting not the yield function but the volume per hectare, which is the argument of the yield function. For instance, this setting could be used to represent the heterogeneity that results from differences in water availability as a result of canal seepage or the type of irrigation materials that are used. If $b_{i}$ stands for the parameter of heterogeneity, the yield function is of the type $r\left(b_{i} V_{i} / s_{i}\right)$. The profit is $\pi_{i}=s_{i}\left[r\left(b_{i} V_{i} / s_{i}\right)\right]$. If the heterogeneity is represented by assuming that $b_{i}=1 / i_{\beta}$, then the results obtained with the previous coefficient $\alpha$ will also be valid by defining $a_{i}=1 / \sqrt{b_{i}}=i^{\beta / 2}$.

We now turn to a field study, where we compare actual and potential allocation rules, calculating the Nash equilibrium associated with ex post rules.

\section{Application to the El Melalsa irrigation scheme}

The El Melalsa irrigation scheme is situated near the city of Kairouan, in central Tunisia. It has been distributing water since 1992 using a pump with a flow of $241 / \mathrm{s}$. It irrigates a complex of 160 ha, which is divided among 54 farmers. Crop rotation is based on the following cycle: wheat from the beginning of November to the end of April, melons the following year from mid-March to the end of June and afterwards a mix of pepper and beans, cropped from the beginning of September to mid-March (Figure 5). Two main periods during the wheat cycle are distinguished: period 1 from the beginning of November to mid-March and period 2 from mid-March to the end of April, i.e. when melons are also sown. The melon is the crop that can give the best income but it is very water intensive and sensitive to water stress. The scheme is situated in a semi-arid region, with a rainy period during winter. The main source of heterogeneity among farmers is significant water losses in most parts of the scheme.

Since the beginning of the scheme, a water turn has been established by the farmers. Each farmer can irrigate as much as he wants once it is his water turn. Hereafter, such an allocation rule is called 'allocation with an unlimited irrigation period'. Moreover, there is no limit put on the total area that can be cropped by any individual. In the El Melalsa irrigation scheme, water is considered a collective good. For instance, a farmer has no recourse if the president and the watermaster decide to grant a greater priority to another farmer and hence to postpone his irrigation turn. In this context, farmers sowed 61 ha

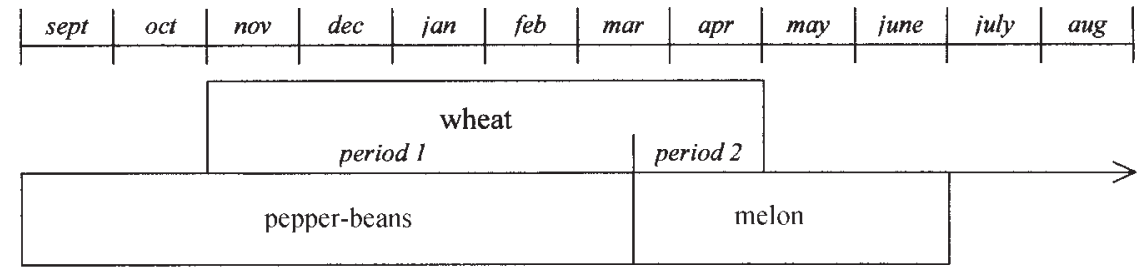

Figure 5. Cultivation periods for the four main crops in El Melalsa. 
of wheat, 21 ha of beans and 27 ha of melons from September 1998 to September 1999. The farmers acknowledged that even if rainfall had been average, such an aggregate tilled area would have led to a very long water turn in March 1999 (approximately 10 days), plants would not have been irrigated enough and, consequently, the overall area could have been assessed as overcropped. As it happened, rainfall was below average and farmers decided to allocate water after examining each case individually, a process that led to a pronounced inequity in the distribution of water.

Farmers' cropping decisions are simulated to check whether the Nash equilibrium associated with the real allocation rule can reflect the observed cropping pattern. Furthermore, the simulation is made when the actual rule is replaced with an ex ante rule based on hours-per-hectare quotas and then with an ex post rule based on controlling the length of water turns.

Ten of the 54 farmers are excluded from consideration as they have their own wells, which are either within or in close proximity to the scheme: these farmers do not participate in the water turn system. Therefore, we distinguish between farmers who own wells outside the scheme (type A) and those who do not own wells at all (type B). Broadly speaking, type A farmers give priority to cash crops outside the scheme and hence have to pay workers if they want to sow the same crops inside the scheme. They will do so only if water access conditions are good.

Farmers' choices are simulated using a model of linear programming under constraints, in a deterministic setting. Details of the simulation are given in Appendix 6.

\subsection{Simulation of different allocation rules}

\subsubsection{Allocation with an unlimited irrigation period}

The method. The initial aggregate tilled area is divided into given allotments for melons, pepper-beans and wheat that can be considered as being suitable from a collective point of view. This crop distribution is introduced into a water balance model based on a day time-step, which calculates the length of the water turn period required to irrigate the whole area satisfactorily. The model then calculates the real evapotranspiration values, which are used to derive a common yield per hectare for all zones in the scheme and for each crop. With such a rule, yields do not depend on the position of the field inside the scheme.

Nevertheless, as a result of seepage losses, the amount of water required is greater the further one goes from the pump. Hence, within each farmer group, $\mathrm{A}$ and $\mathrm{B}$, there is a subgroup whose fields are in outlying areas of the scheme, and who decide to grow melons no longer because of prohibitive water charges. Therefore, a seepage loss threshold can be defined, for both types A and B, which divides each type into two subgroups: farmers of subgroups $\mathrm{A} 1$ and $\mathrm{B} 1$ have a seepage coefficient lower than this threshold and grow melon whereas those of subgroups A2 and B2 have coefficients greater than the threshold and cultivate only wheat and pepper-beans. The value of such a threshold is calculated from the values of the different crop yields. 
Then, an average farmer's profile for each sub-type is calculated and constrained optimisation is performed to simulate the cropping choice of the representative farmer (see Appendix 6). The overall cropping pattern is then compared with the initial one. With this model, the area cropped with wheat is actually constant, hence the only possible changes involve the distribution between melon and beans. If the calculated total area under melons is larger (smaller) than the initial assumed area, in the next step the next assumed area under melons is increased (decreased), until convergence is attained.

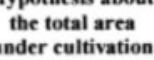

Yields

Group size

(in terms of the owned area inside

the scheme)
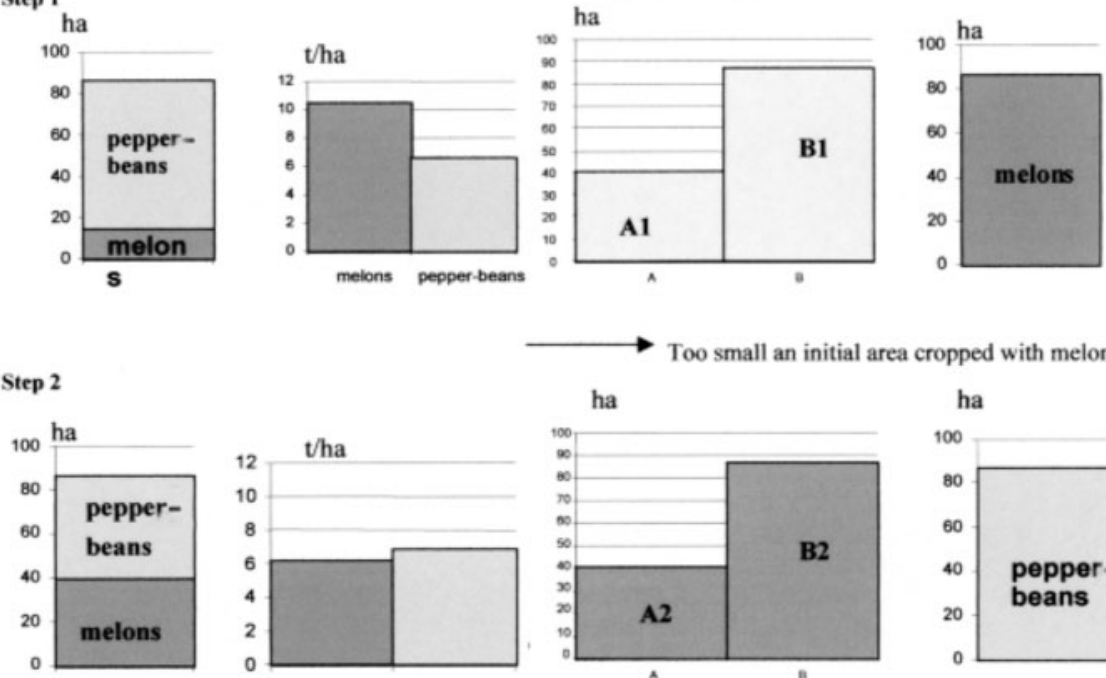

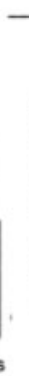

Too small an initial area cropped with melons

Step 3
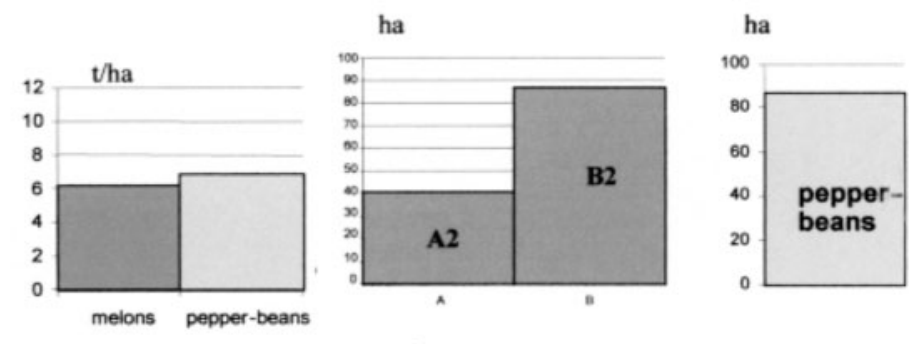

Too large an initial area cropped with melons
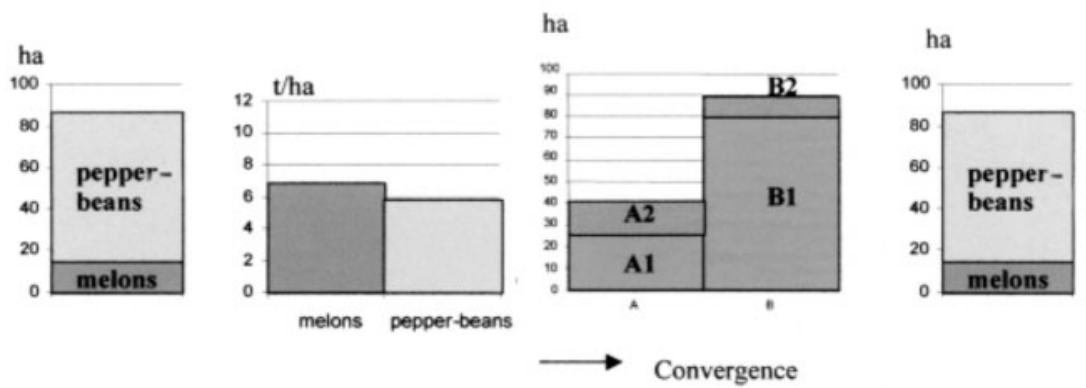

Figure 6. Simulation of different stages leading to the cropping pattern at equilibrium. Typology consists of four groups: A owns a well outside the scheme; B does not own a well outside the scheme; 1 grows melon; 2 does not grow melon. 
Application. The initial simulated area is made up of 15 ha of melons and 71.6 ha of pepper-beans. The water turn length is hence short and the harvests are good (step 1 of Figure 6). The thresholds are, thus, about 0.25 for type A and 0.15 for type B. All farmers belong to either A1 or B1, and hence grow melons.

In fact, farmers always plant only one-third of their usable area with wheat (see Appendix 6). Hence, the total possible cropping pattern always satisfies the constraint that the sum of melon and pepper-beans areas is equal to 86.6 ha.

After some trials, convergence is attained for a total sown area of 28 ha of melons. In Figure 6, two extreme cropping patterns and the one at convergence are described. There is necessarily convergence, because it is a 'fixed point' situation: an initial scenario with the whole area planted to melons will lead to large-scale planting of pepper-beans, just as a large area under pepper-beans at the beginning will lead to a situation with all farmers growing melons later. The only issue then is one of continuity in farmers' strategic choices. This continuity would be guaranteed if many different types of farmers were created. With the given typology, convergence was not guaranteed. For instance, Figure 6 shows a drastic change in the value of the threshold between two initial cropping patterns that are similar. This is caused by the fact that each time the simulation is made with only four average farmers representing each of the subgroups. The shift corresponds to a change in the optimal base for one or even two of the subgroups. It would have been possible to obtain a more progressive convergence by defining more groups of farmers. Besides, even if the total area under wheat is constant, the wheat yield depends on the relative shares of melons and pepper-beans. However, this wheat yield is not represented in Figure 6 because it is not accounted for in farmers' cropping choices.

At convergence, the threshold is 0.45 for type A, which results in group A1 being made up of nine farmers who farm a total area of 26.8 ha. The threshold is the same for type B. However, B1 is made up of 26 farmers representing an aggregate area of 80.6 ha (see Table A2 in Appendix 6). Furthermore, average type A1 owns 8 ha outside the scheme and because of labour costs, sows only 0.33 ha of melons within the scheme, i.e. 4.4 ha is given to melons for the whole subgroup A1.

The areas simulated are similar to the real ones (Figure 7). Regarding water stress, the survey produced an estimate of the proportion of optimal yield actually attained equal to 0.26 , compared with the 0.45 simulated. The difference can be explained by high levels of inequity in sharing water.

Farmers themselves have confirmed our results. In their opinion, farmers close to the pump plant a considerable area and thus force other farmers to withdraw or adopt different strategies, such as investing in a well and/or not sowing melons.

\subsubsection{Ex ante allocation}

The change in farmers' choices is simulated here in the situation where the water turn length is fixed by allotting to each farmer a quota of hours in 


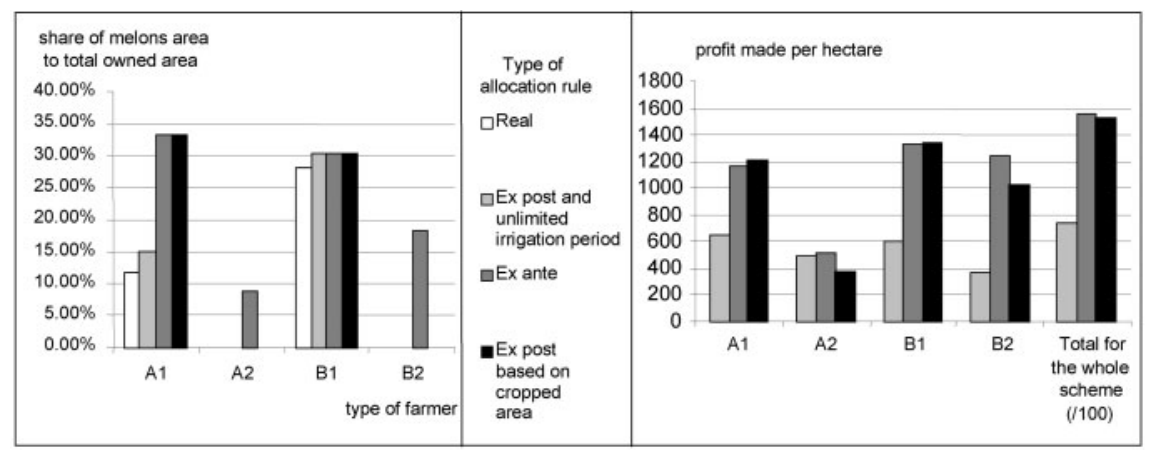

Figure 7. For each type of farmer, (a) shows proportion of melon area to total area, and (b) shows profit per hectare inside the scheme for different kinds of allocation.

proportion to the area he owns. Thus, each farmer makes his own cropping choices, independently of others. As a result, each farmer grows melons on a part of his farm (Figure 7).

\subsubsection{Ex post allocation based on cropped area}

The setting used here is the same as the one used with the ex ante rule but here the volume delivered during period 2 is proportional to the area devoted to melons. We also assume that melons must receive the necessary water volume; farmers nevertheless have the opportunity to use part of the water allocated to them to irrigate wheat during period 2. Convergence is attained with a threshold of 0.32 for both types, i.e. a total area of 40 ha is cropped with melons. With the exception of a single type B farmer, the same partition is obtained as with the ex post allocation rule with an unlimited irrigation period.

\subsection{Comparison}

It appears that the ex post allocation rule based on cropped area share creates more total value than the existing rule (Figure 7) because it makes control of the length of water turns possible. Moreover, this ex post rule creates almost as much value as the ex ante allocation. With reference to what has been shown in the theoretical section, heterogeneity regarding seepage losses in this scheme can be considered average. In addition, with the ex ante rule and the ex post rule based on the control of water turn length, farmers of subgroup A1 find it worth while to hire workers to sow melons inside the scheme.

\section{Conclusion}

This study explores the question of what would be the best water allocation rule when (i) farmers can choose the area they put under crops and (ii) the Manager knows only the global distribution of farmers' abilities to create value from water. It is based on the assumption that the Nash equilibrium 
accurately describes the outcome of strategic interactions for a given rule, i.e. when farmers cannot or do not change the rule. The field study conducted in Tunisia confirms this hypothesis, which is also reported in other analyses (e.g. Ostrom, 2000). The Manager can implement a set of contracts equivalent to a revelation mechanism. Nevertheless, because of the need to provide specific incentives, the Manager might not be able to pay water production costs.

The Manager can use simpler rules. An ex ante allocation rule will be efficient if the group is homogeneous whereas, in the other case, an ex post allocation will create more value. However, the latter rule leads to large differences in farmers' profits. The best solution consists then in linking the ex post allocation rule with a high water tariff, and ensuring that the taxes collected are redistributed to meet equity objectives. Although being somewhat equivalent to the definition of individual shares in the resource, this rule has the main advantage of preserving the collective status of water. Its main drawback is the existence of important monetary transfers. To our knowledge, there is no real-world example of such an allocation rule where the tariff has been chosen deliberately high. However, in the future, as water user associations become more mature, this kind of tax may be more easily adopted.

If this rule cannot be implemented because of the monetary transfers, a mixed solution between ex ante and ex post allocation rules may be of interest. Hence, the ex post allocation rules sometimes lead to a satisfactory total created value, but they almost always fail to meet standard equity objectives. Three main reasons can nevertheless explain their substantial presence in the field. First, the rule may have been chosen in times where there was no water scarcity. Second, agronomic constraints sometimes prevent farmers from growing cash crops every year; a rotation takes place among those who take advantage of the ex post allocation rule from year to year. Third, the rule can be profitable for some farmers who succeed in maintaining the ex post rule. In the El Melalsa irrigation scheme, these three reasons can together explain the existence of the ex post allocation rule.

A further development of the theoretical approach would be to use game theory (co-operative game, bargaining) to model the outcome of negotiations among farmers about the choice of the allocation rule, using the previous non-co-operative game results.

\section{Acknowledgement}

The author is grateful to an anonymous referee for insightful comments. The research was made possible by co-operation between the French research institutes IRD and Cemagref. In Tunisia, the research was conducted within the MERGUSIE project, led by the Tunisian Department of Agriculture, INAT and IRD.

\section{References}

Baland, J.-M. and Platteau, J.-P. (1999). The ambiguous impact of inequality on local resource management. World Development 27(5): 773-788. 
Bédoucha, G. (1984). L'eau, l'ami du puissant. Une communauté oasienne du Sud tunisien. Paris: édition des archives contemporaines, Centre National de la Recherche Scientifique.

Dayton-Johnson, J. (2000a). Choosing rules to govern the Commons: a model with evidence from Mexico. Journal of Economic Behavior and Organization 42: 19-41.

Dayton-Johnson, J. (2000b). Determinants of collective action on the local commons: a model with evidence from Mexico. Journal of Development Economics 62: 181-208.

Faysse, N. (2001). L'influence des règles collectives d'allocation de l'eau sur les choix stratégiques des agriculteurs. Ph.D. thesis, Université Paris X Nanterre, Paris. Available at: http://www.montpellier.cemagref.fr/doc/publications/theses/nicolas-faysse.html, last accessed September 2003.

Garrido, A. (2000). A mathematical programming model applied to the study of water markets within the Spanish agricultural sector. Annals of Operations Research 94: $105-123$.

Gillingham, M. (1999). Gaining access to water: formal and working rules of indigenous irrigation management on Mount Kilimanjaro, Tanzania. Natural Resources Journal 39: 419-441.

Guesnerie, R. (1995). A Contribution to Pure Theory of Taxation. Cambridge: Cambridge University Press.

Moulin, H. (1988). Axioms of Cooperative Decision Making. Econometric Society Monographs. Cambridge: Cambridge University Press.

Olson, M. (1965). The Logic of Collective Action: Public Goods and the Theory of Groups. Cambridge, MA: Harvard University Press.

Ostrom, E. (2000). A behavioral approach to the rational choice theory of collective action. In M. McGinnis (ed.), Polycentric Games and Institutions. Ann Arbor, MI: University of Michigan Press.

Ostrom, E., Gardner, R. and Walker, J. (1994). Rules, Games and Common Pool Resources. Ann Arbor, MI: University of Michigan Press.

Platteau, J.-P. and Seki, E. (1998). Coordination and pooling arrangements in Japanese coastal fisheries. Working Paper 208. Namur: University of Namur.

Schlager, E., Blomquist, W. and Tang, S.Y. (1994). Mobile flows, storage, and selforganized institutions for governing common pool resources. Land Economics 70(3): 294-317.

Small, L. and Rimal, A. (1996). Effects of alternative water distribution rules on irrigation system performance: a simulation analysis. Irrigation and Drainage Systems 10: 25-45.

Steiner, R. and Walter, M. (1992). The effect of allocation and scheduling rules on equity and productivity in irrigation systems. Agricultural Water Management 21: 297-312.

Vermillion, D. and Garces-Restrepo, C. (1996). Results of management turnover in two irrigation districts in Colombia. Research Report 4. Colombo: International Water Management Institute (IWMI).

\section{Appendix 1: Choice of a single farmer}

We assume that the farmer is interested in using the entire allocated volume $V_{0}$. The farmer's choice of what area to cultivate is the solution of the problem

$$
\operatorname{Max}_{s_{i}} \pi_{i}=s_{i}\left[a_{i} r\left(\frac{V_{0}}{s_{i}}\right)-k\right]-w_{0} V_{0}
$$

for $s_{i} \leq s_{m}$ and $\pi_{i} \geq 0$. 
Because the yield function is concave,

$$
\frac{\partial^{2} \pi_{i}}{\partial s^{2}}=\frac{V_{0}}{s_{i}^{2}} r^{\prime \prime}\left(\frac{V_{0}}{s_{i}}\right) \leq 0
$$

the profit function is also concave in $s_{i}$. Hence if $\mu$ is the Lagrangian multiplier associated with the first constraint of programme (A1), the volume per hectare chosen by the farmer at the optimum $v_{i}^{*}=V_{0} / s_{i}$ is defined by

$$
a_{i} r\left(v_{i}^{*}\right)-a_{i} v_{i}^{*} r^{\prime}\left(v_{i}^{*}\right)-k-\mu=0 .
$$

Let $g(u)=r(u)-u r^{\prime}(u)$. If the optimal area $s_{i}^{*}$ is smaller than $s_{m}, s_{i}^{*}$ is given by $g\left(v_{i}^{*}\right)=k / a_{i}$. Hence, as $g$ is reversible, the solution of (A1) is

$$
s_{i}^{*}=\min \left[s_{m}, \frac{V_{0}}{g^{(-1)}\left(k / a_{i}\right)}\right] .
$$

\section{Appendix 2: The market can attain the optimum}

Let there be a market for water among farmers. The farmers trade the volumes allotted to them for the price $p$ per unit volume and, if the initial endowment is $V_{i, 0}$, the farmer's programme is

$$
\operatorname{Max}_{s_{i}, V_{i}} \pi_{i}=s_{i}\left[a_{i} r\left(\frac{V_{i}}{s_{i}}\right)-k\right]-p\left(V_{i}-V_{i, 0}\right) .
$$

for $s_{i} \leq s_{m}$.

The first-order condition with respect to $V_{i}$ yields

$$
a_{i} r^{\prime}\left[\frac{V_{i}}{s_{i}}\right]=p .
$$

The first-order condition with respect to $s$ is

$$
\frac{\partial \pi_{i}}{\partial s}=a_{i} r\left(\frac{V_{i}}{s_{i}}\right)-a_{i}\left(\frac{V_{i}}{s_{i}}\right) r^{\prime}\left(\frac{V_{i}}{s_{i}}\right)=k+\mu_{i} .
$$

These equations are the same as the equations ((A6) and (A7)) that define optimal allocation (see Appendix 3). With the constraint on the total available volume of water, the resolution is the same as the one for optimal allocation, and hence also yields the optimum for value created from water. Moreover, the equilibrium price $p$ is also the Lagrange multiplier $\lambda$ associated with the optimal allocation rule.

\section{Appendix 3: Optimal allocation}

The Lagrangian function of decision problem (3) is

$$
\Lambda=\sum s_{i}\left[a_{i} r\left(\frac{V}{s_{i}}\right)-k\right]+\left(\lambda-w_{0}\right) V-\lambda \sum V_{i}-\sum \mu_{i}\left(s_{i}-s_{m}\right)
$$

where $\lambda$ is the Lagrange multiplier associated with the constraint $\sum V_{i} \leq V$ and $\left(\mu_{i}\right)_{1 \leq i \leq n}$ are the Lagrange multipliers associated with the $n$ constraints $s_{i} \leq s_{m}$. The differentiation of the Lagrangian function with respect to the volumes $V_{i}$ leads to

$$
\forall i \in \mathrm{I} \quad a_{i} r^{\prime}\left(\frac{V_{i}}{s_{i}}\right)=\lambda .
$$

This first condition equalises the marginal value of water among the farmers. Let $v_{i}^{*}=V_{i} / s_{i}$ be the volume per hectare for farmer $i$ in the solution of (3). Consequently,

$$
\forall i \in \mathrm{I} \quad v_{i}^{*}=\left(r^{\prime}\right)^{(-1)}\left(\frac{\lambda}{a_{i}}\right)
$$


Because function $r^{\prime}$ decreases, $r^{\prime(-1)}$ also decreases. Therefore, $v_{i}^{*}$ increases in $a_{i}$ and so decreases in $i$. Hence, the farmers who are able to create more value obtain a larger volume per hectare than the others. Furthermore, the differentiation of the Lagrangian function with respect to the individual area under cultivation $s_{i}$ gives

$$
\forall i \in \mathrm{I} \quad a_{i} r\left(v_{i}^{*}\right)-v_{i}^{*} a_{i} r^{\prime}\left(v_{i}^{*}\right)=a_{i} g\left(v_{i}^{*}\right)=k+\mu_{i} .
$$

Therefore we can distinguish two groups of farmers: those for whom $\mu_{i}=0$, thus $s_{i} \leq s_{m}$ and the volume allocated per hectare by the Manager corresponds to the one that the farmer would have chosen if he was alone; and those for whom $\mu_{i}>0$, thus $s_{i}=s_{m}$ and the volume per hectare is larger than the one the farmer would have irrigated if he was alone.

With equation (A6), $v_{i}$ is increasing in $a$, and the function $g(u)$ is increasing. Hence, with (A7), if $a_{i}>a_{j}$ then $a_{i} g\left(v_{i}^{*}\right)>a_{j} g\left(v_{j}^{*}\right)$ and $\mu_{i}>\mu_{j}$. Finally $a_{1}>a_{2}>\cdots>a_{n}$ yields $\mu_{1}>\mu_{2}>\cdots>\mu_{n}$.

Suppose that farmer $q$ is the first in the set of farmers ordered from one to $n$ who satisfies $\mu_{q}=0$. Thus, $a_{q} g\left(v_{q}^{*}\right)=k$. Consequently, for $i<q, s_{q}=s_{m}$. All farmers with a lower index will have sown their total area. For the farmers for whom $i>q$, if one supposes that $s_{i}>0$, then $v_{i}^{*}<v_{q}^{*}$, so $g\left(v_{i}^{*}\right)>g\left(v_{q}^{*}\right)$, and $k / a_{i}>k / a_{q}$ gives $a_{i}<a_{q}$, which is impossible. Hence $s_{i}=0$ for $i>q$, because if farmer $q$ does not cultivate his total area, a fortiori a farmer with lesser technical knowledge will not do better on any part of his own area.

Finally, for all farmers with an index $i$ lower than $q, a_{i} r^{\prime}\left(V_{i} / s_{m}\right)=\lambda$ so $V_{i}=$ $s_{m}\left(r^{\prime}\right)^{(-1)}\left(\lambda / a_{i}\right)$. This yields $V=s_{m} \sum_{i=1}^{q}\left(r^{\prime}\right)^{(-1)}\left(\lambda / a_{i}\right)$, which gives an implicit function $\lambda(q)$.

\section{Appendix 4: Revelation mechanism}

The proof consists simply in checking that, with the given functions $f_{r}$ and $t_{r}$, the farmers will announce their true coefficients of ability, whereas the pattern of areas cultivated and volumes allocated are similar to those at the optimal allocation.

First, suppose that a farmer, having a coefficient $a_{i}$, decides to announce a coefficient $\tilde{a}_{i} \geq a_{q}$. Then, the definition of his profit (equation (7)) is specified by using the revelation functions as defined in equations (5) and (6). Let $\pi\left(a_{i}, \tilde{a}_{i}\right)$ be the profit of a farmer having an ability coefficient $a_{i}$ and announcing $\tilde{a}_{i}$ :

$$
\begin{aligned}
\pi\left(a_{i}, \tilde{a}_{i}\right) & =s_{m}\left\{a_{i} r\left[\left(r^{\prime}\right)^{(-1)}\left(\frac{\lambda}{\tilde{a}_{i}}\right)\right]-k\right\}-s_{m}\left\{\tilde{a}_{i} r\left[\left(r^{\prime}\right)^{(-1)}\left(\frac{\lambda}{\tilde{a}_{i}}\right)\right]-\int_{a_{q}}^{\tilde{a}_{i}} r\left[\left(r^{\prime}\right)^{(-1)}\left(\frac{\lambda}{u}\right)\right] \mathrm{d} u\right\} \\
& =\pi\left(a_{i}, a_{i}\right)+s_{m}\left\{\int_{a_{i}}^{\tilde{a}_{i}} r\left[\left(r^{\prime}\right)^{(-1)}\left(\frac{\lambda}{u}\right)\right] \mathrm{d} u-\left(\tilde{a}_{i}-a_{i}\right) r\left[\left(r^{\prime}\right)^{(-1)}\left(\frac{\lambda}{\tilde{a}_{i}}\right)\right]\right\} \\
& =\pi\left(a_{i}, a_{i}\right)+s_{m} \int_{a_{i}}^{\tilde{a}_{i}}\left\{r\left[\left(r^{\prime}\right)^{(-1)}\left(\frac{\lambda}{u}\right)\right]-r\left[\left(r^{\prime}\right)^{(-1)}\left(\frac{\lambda}{\tilde{a}_{i}}\right)\right]\right\} \mathrm{d} u .
\end{aligned}
$$

The function $r\left[\left(r^{\prime}\right)^{(-1)}(\lambda / u)\right]$ is increasing in $u$, hence $\forall \tilde{a}_{i}, \pi\left(a_{i}, \tilde{a}_{i}\right) \leq \pi\left(a_{i}, a_{i}\right)$. Therefore, the farmer achieves the best profit if he announces his true coefficient of ability $a_{i}$.

In addition, the volume per hectare allocated to each farmer is $v_{i}^{*}=\left(r^{\prime}\right)^{(-1)}\left(\lambda / a_{i}\right)$, with the $\lambda$ defined for the optimal allocation. Therefore, both the distribution of land under crops and the distribution of water are identical to those for optimal allocation.

\section{Appendix 5: Ex post allocation}

The function

$$
z(x)=s_{m}\left[a_{x} r\left(\frac{V}{s_{m} x}\right)-k-w \frac{V}{s_{m} x}\right]
$$


is decreasing in $x$. From equation (8), the pivotal farmer $p(w)$ is the one for whom $\pi[p(w)]=z[p(w)]=0$. There will be overcropping if $p(w)>q$, where $q$ is the pivotal farmer for the optimal allocation. Hence, the overcropping situation can be defined by

$$
z(q)=s_{m}\left[a_{q} r\left(\frac{V}{s_{m} q}\right)-k-w \frac{V}{s_{m} q}\right]>0 .
$$

There is an overcropping situation if the tariff

$$
w<\left\{s_{m} q\left[a_{q} r\left(\frac{V}{s_{m} q}\right)-k\right]\right\} / V .
$$

\section{Appendix 6: The model for cropping decisions in El Melalsa}

The farmers' choices are simulated with linear programming models in a deterministic context. Two slightly different models were used for ex post and ex ante rules.

For the purposes of this paper, pepper followed by beans is treated as a single crop. Because water is expensive in the remote parts of the scheme, it is assumed that a farmer may choose not to irrigate wheat and beans as much as would be necessary. On the contrary, he will always irrigate melons to prevent water stress to this crop.

For farmers who have access to water from outside the scheme, we assume that it is always worth while to irrigate beans as much as is necessary, as water from private wells costs less and, according to field observations, farmers can also decide not to irrigate their wheat outside the scheme sufficiently because of the limited pumping capacity of wells.

The characteristics of a farmer are: the area he can cultivate inside $(T A L)$ and outside (TALO) the scheme, the average loss coefficient $a(a=1$ if there is no loss and $a$ decreases when losses increase), his farm labour force $(L F)$ and a potential daily volume from a well $\left(V_{d o}\right)$ that can be used outside the scheme.

The decision variables are: areas inside the scheme sown with wheat, pepper-beans and melons $\left(S_{w h e}, S_{p b}, S_{m e l}\right)$; and the equivalent variables outside $\left(S_{w h e o}, S_{p b o}, S_{\text {melo }}\right)$; the total volume allocated for growing wheat during periods 1 and $2\left(V_{w h e 1}, V_{w h e 2}\right)$; the volume allocated for pepper-beans $\left(V_{p b}\right)$; the corresponding volumes outside the scheme $\left(V_{\text {wheo }}\right.$, $\left.V_{w h e o 2}\right)$; and the possibility of hiring workers in March $\left(R_{l f m a}\right)$ and in June $\left(R_{l f j n}\right)$.

The constraints common to both the models are

- the limit on the area that can be cultivated inside the scheme $S_{w h e}+S_{p b}+S_{m e l} \leq T A L$ and the corresponding limit outside;

- the impossibility of growing melons on a parcel inside the scheme for more than one year out of three: $S_{m e l} \leq T A L / 3$ and the same condition holding outside-because of pest problems;

- the obligation to sow wheat at least one year out of three, both inside the scheme: $S_{\text {whe }} \geq T A L / 3$, and outside: $S_{\text {wheo }} \geq T A L O / 3$ - a widespread food safety strategy;

- the work force constraints in March and June.

When a farmer is able to choose not to apply all necessary water, we use the following very approximate yield function:

$$
r=r_{m}\left[1-k_{y}\left(1-\frac{a V+\text { s.rain }}{s \sum M E T}\right)\right]
$$

where $r$ is the actual crop yield, $r_{m}$ is the maximal crop yield, $k_{y}$ the coefficient of water stress sensibility, $V$ the applied volume, $\sum M E T$ the total maximal evapotranspiration during the period under consideration and $s$ the tilled area. If $P$ stands for the price of the crop, $k$ the input costs and $w$ the water tariff, then the profit made with this crop is

$$
\begin{aligned}
\pi & =(P . r-k) s-w V \\
& =\alpha . s+(a \beta-w) . V
\end{aligned}
$$


where

$$
\alpha=P . r_{m}\left[1-k_{y}\left(1-\frac{\text { rain }}{\sum M E T}\right)\right]-k, \quad \beta=P . r_{m} \frac{k_{y}}{\sum M E T} .
$$

The same formula will be used for wheat, with $V=V_{\text {whe1 }}+V_{\text {whe2 }}$.

Regarding melons, the water required to irrigate melons adequately is $V_{m e l}=$ $\left(\sum M E T-\right.$ rain $) / a$, hence $\pi_{m e l}=\left(P_{\text {mel }} \cdot r_{m}-k\right) s-w \cdot\left(\sum M E T-\right.$ rain $\left./ a\right)$.

One has also to verify that for each period the volume of water used is lower than or equal to the requirement when losses are taken into account:

$$
\left\{\begin{array}{l}
-\sum M E T_{p b} \cdot S_{p b}+a V_{p b} \leq \text { rainpb } \\
-\sum M E T_{\text {whe1 }} \cdot S_{\text {whe }}+a V_{\text {whe } 1} \leq \text { rain } 1 \\
-\sum M E T_{\text {whe } 2} \cdot S_{\text {whe } 2}+a V_{\text {whe } 2} \leq \text { rain } 2 .
\end{array}\right.
$$

Melons require $550 \mathrm{~m}^{3}$ at the beginning of period 2 because more water is needed for sowing. The water tariff is fixed at 0.041 Tunisian Dinars per cubic meter $\left(\mathrm{DT} / \mathrm{m}^{3}\right)$ inside the scheme and $0.02 \mathrm{DT} / \mathrm{m}^{3}$ outside the scheme for those who use a well. ${ }^{4}$ Labour obtained outside costs $5 \mathrm{DT}$ a day per worker. Finally, the profits earned outside the scheme are $1108 \mathrm{DT} /$ ha for pepper-beans and $2857 \mathrm{DT} /$ ha for melon. Regarding the collective resource, the pump functions 10 hours a day from 1 September to 15 March and 20 hours a day outside the period.

In the various simulations made, wheat is never profitable so it is always sown at minimum levels, i.e. an aggregate area of 43.35 ha in this case. In other words, the aggregate areas under crops are situated on a segment $S_{m e l}+S_{p b}=86.65$ ha.

Table Al gives the main figures used in the simulation.

\section{Additional assumptions for unlimited water turn period rule}

We use the following elements:

- the water turn is at least 1 week long;

- farmers irrigate wheat and pepper-beans up to 50 per cent of the maximum between soil reservoir level and root reservoir level, to take into account that farmers do not irrigate wheat and pepper-beans up to the MET;

- for a cultivated area of 130 ha the average water loss is 50 per cent, which also takes into account periodic pump breakdowns.

\section{Complements to ex ante rule}

Let $V_{d}=1728 \mathrm{~m}^{3} /$ day be the daily volume delivered by the pump. Let $n d b p e r 1=135$ and $n d$ bper $2=46$ be the number of days within periods 1 and 2 , respectively. The ex ante rule stipulates that each farmer can irrigate up to $V_{d}\left(T A L / \sum T A L\right)$ per day. Consequently, the new constraints in period 1 are

$$
\left\{\begin{array}{l}
V_{\text {whe } 1}+V_{p b} \leq V_{d} \frac{T A L}{\sum T A L} . n b d p e r 1 \\
\text { and outside 1900.S } S_{p b o}+V_{\text {wheo } 1} \leq V_{d o} . n b d p e r 1 .
\end{array}\right.
$$

Similarly, during period 2:

$$
\left\{\begin{array}{l}
\frac{\sum M E T-\text { rain }}{a} S_{\text {mel }}+V_{\text {whe } 2} \leq V_{d} . T A L . \text {.nbdper } 2 \\
\frac{\sum M E T-\text { rain }}{a} S_{\text {melo }}+V_{\text {wheo } 2} \leq V_{d o} . \text { TALO.nbdper } 2 .
\end{array}\right.
$$

Here, each type of farmer decides to sow all possible crops (Figure 7). 
Table A2. Characteristics of farmer types at convergence

\begin{tabular}{lrllllll}
\hline Type & Size & $\begin{array}{l}\text { Average } \\
\text { arable land } \\
\text { per farmer } \\
\text { in the } \\
\text { scheme (ha) }\end{array}$ & $\begin{array}{l}\text { Total arable } \\
\text { land in the } \\
\text { scheme (ha) }\end{array}$ & $\begin{array}{l}\text { Average } \\
\text { arable land } \\
\text { outside the } \\
\text { scheme (ha) }\end{array}$ & $\begin{array}{l}\text { Labour } \\
\text { force }\end{array}$ & $\begin{array}{l}\text { Average } \\
\text { losses } \\
\text { coefficient }\end{array}$ & $\begin{array}{l}\text { Daily volume } \\
\text { available } \\
\text { outside the } \\
\left.\text { scheme (m }{ }^{3}\right)\end{array}$ \\
\hline A1 & 9 & 2.9 & 26.1 & 8 & 2.3 & 0.77 & 346 \\
A2 & 3 & 4.8 & 14.4 & 12 & 2.7 & 0.31 & 346 \\
B1 & 26 & 3.1 & 80.6 & 6 & 1.9 & 0.75 & 0 \\
B2 & 6 & 1.4 & 8.4 & 0.6 & 2.2 & 0.28 & 0 \\
\hline
\end{tabular}

\section{Complements to ex post rule according to the area cultivated}

During period 2, each farmer receives a total volume $V=n b d p e r 2\left(S_{\text {mel }} V_{d} / S_{\text {totmel }}\right)=\gamma S_{\text {mel }}$, where $S_{\text {totmel }}$ stands for the aggregate area under melons. Hence, the equation representing water needs during period 2 becomes 3650. $S_{m e l}+V_{\text {whe } 2} \leq \gamma \cdot a . S_{m e l}$.

Corresponding author: Nicolas Faysse, International Water Management Institute (IWMI), 141 Cresswell Street, Silverton 0184, Pretoria, Private Bag X813, Silverton 0127, Pretoria, South Africa. E-mail: Nicolas.Faysse@voila.fr 